\title{
Proverbs from the Viewpoint of Translation
}

\author{
Azizollah Dabaghi \\ Department of Foreign Languages, Isfahan University, Isfahan, Iran \\ Elham Pishbin \\ Department of Foreign Languages, Isfahan University, Isfahan, Iran \\ Leila Niknasab \\ Department of Foreign Languages, Isfahan University, Isfahan, Iran \\ Email: Leilaniknasab@yahoo.com
}

\begin{abstract}
Undoubtedly passing the world of translation opens new windows toward getting familiar with literature, language and culture of those who think, behave and look at the world in a similar and/or different manners. Although going through many linguistic features seems much less problematic, catching what is going to be transferred through non-linguistic ones is the most problematic to deal with. Among those nonlinguistic features, including figurative devices, proverbs are going to be examined in this paper. First some definitions are represented, then proverbs' characteristics and classifications are given and at the end we examine strategies suggested for translation of proverbs by different theorists. Examples of English and Persian proverbs are presented and compared in order to clarify language differences and/or similarities and translating strategies.
\end{abstract}

Index Terms - proverb, translation strategies, culture

\section{INTRODUCTION}

The study of proverbs is called paremiology (from Greek $\pi \alpha \rho o l \mu i \alpha$ - paroimía, "proverb") and can be dated back as far as Aristotle (Wikipedia, the free encyclopedia). According to Kindstrand (1978) \& Russo (1983) "the definition of a proverb has caused scholars from many disciplines much chagrin over the centuries. Many attempts at definition have been made from Aristotle to the present time, ranging from philosophical considerations to cut-and-dry lexicographical definitions" (in Meider, 2004:1).

Meider (1985: 119) has defined the proverb as "a short, generally known sentence of the folk which contains wisdom, truth, morals, and traditional views in a metaphorical, fixed and memorizable form and which is handed down from generation to generation".

He also points to some proverbs which refer to the definition of proverbs for example; "Proverbs are the children of experience," "Proverbs are the wisdom of the streets," and "Proverbs are true words." "Proverbs obviously contain a lot of common sense, experience, wisdom, and truth, and as such they represent ready-made traditional strategies in oral speech acts and writings from high literature to the mass media" (ibid: 3-4.)

Mollanazar (2001: 53) has defined the proverb as "a unit of meaning in a specific context through which the speaker and hearer arrives at the same meaning."

And the last but not the least Norrick (1985:78) has proposed the following definition for the proverb:"The proverb is a traditional, conversational, didactic genre with general meaning, a potential free conversational turn, preferably with figurative meaning."

Characteristics of proverbs

Different characteristics have been proposed for proverbs by various scholars in the field of paremiology. Here the ideas of two influential scholars will be referenced. Norrick (1985: 32-34) gathering the disperse features proposed by various scholars, has proposed the following characteristics which help us to identify the proverbs from other similar items. These characteristics are as follow:

Proverbs are self-contained: Seiler has argued that proverbs must be self-contained by which he means that none of their essential grammatical units may be replaced. In Norrick's words "Seiler introduces this definitional criterion solely to distinguish proverbs from proverbial phrases. With reference to these characteristics in Norrick's words "proverbial phrases like "to face the music" and "Brown as a berry" are immediately excluded from the class of proverbs because they lack precisely essential grammatical units, which can thus be substituted into them at will".

Proverbs are (propositional) statement: Abrahams is perhaps more precise in requiring the proverb to be a full statement.

Proverbs are (grammatical) sentences: Taylor determines that proverbs must be complete (if elliptical) sentences. Besides, writers such as Abrahams, Holneck, and Meider, also accept complete sentence status as a property of the proverbs. 
Proverbs are tradition: The traditional nature of proverbs correlates closely with their status as items of folkloric.

Another theorist who has mentioned some characteristics of proverbs is Trench (1853).He states that three things go to the constituting of a proverb, i. e. shortness, sense, and salt. These characteristics are elaborated on briefly (16-17):

1. Shortness (Brevity): According to Trench "a proverb must have shortness; it must be succinct, utterable in a breath". He points out that "it is, indeed, quite certain that a good proverb will be short-as is compatible with full and forcible conveying of that which it intends. Brevity, "the soul of wit", will be eminently the soul of a proverb's wit. Oftentimes it will consist of two, three, or four, and these sometimes monosyllabic words". This characteristic is obvious in proverbs such as extremes meet; forewarned, forearmed and a thousand more. Furthermore he mentions that:

Shortness is only a relative term, and it would perhaps be more accurate to say that a proverb must be concise-cut down, that is, to the fewest possible words; condensed, quintessential wisdom but that, if only it fulfill this condition of being as short as possible, it need not be absolutely very short, there are sufficient examples to prove this.

2. Sense: Trench states that the sense is sometimes scarified to alliteration.

3. Salt: Trench asserts that "a proverb must have salt, that is, besides its good sense it must in its manner and outward form being pointed and pungent, having a sting in it, a barb which shall not suffer it to drop lightly from the memory".

Regarding this characteristic Marvin (1916, in Trench, 1855: 17) declares that:

Wit and humor in proverbs are common with men who live in favored lands. There is wisdom as well as pleasures in quoting an adage for instructions that is likely to be received with a laugh or a smile, and it is no wonder that in countries where there are liberty and opportunity a large number of such adages should be in use. It is, however, different where misrule and oppression depress the spirits of the people, or where the struggle for existence is so severe that life is filled with anger. In such places there is an incongruity in pleasantries of speech, and wit and humor seem out of place. Yet even under such circumstances nature is true to herself, and in the face of the most adverse conditions men will sometimes quote an amusing aphorism and droll sayings will suddenly spring into popularity; indeed some of the wittiest phrases had their origin in times of distress and suffering. Proverbs have been called " the tears of humanity," not because they are sad, for many are joyous; not because they are depressing, for many are filled with laughter, but because so many have made appearance when the lives of people were embittered by hard toil or made perilous by threatened injury and loss.

Arora (1984) in her article has investigated the stylistic features of proverbs which are as follow:

Alliteration (Forgive and forget)

parallelism (Nothing ventured, nothing gained)

rhyme (When the cat is away, the mice will play)

ellipsis (Once bitten, twice shy)

She also proposed some internal features of proverbs which are as follow:

hyperbole (All is fair in love and war)

paradox (For there to be peace there must first be war)

personification (Hunger is the best cook)

\section{ClassificAtion OF PROVERBS}

Different categorizations of proverbs have been proposed by different scholars. For the purpose of the present article two main categorizations will be presented.

The first categorization is one outlined by Norrick (in Honeck, 1997:130-135) who analyzed a sample of the proverbs from the oxford dictionary of English Proverbs. He developed a more empirically oriented and less grandiose schematization that categorizes proverbs according to the type of figuration they use. He distinguished five types of figurative proverbs: synecdoche, metaphoric, metonymic, hyperbolic, and paradoxical. It must be mentioned that in Norrick's words figurative proverbs have figurative meanings that differ from their literal meaning. These types will be explored on briefly:

\section{A. Synecdoche Proverbs}

The proverbs in which the literal reading and standard proverbial interpretation or SPI "stand in a relation of macrocosm to microcosm" (ibid: 108). This includes examples such as the early bird catches the worm, make hay while the sun shines, and Fair words break no bones. In these proverbs, the literal meaning is quite different from the figurative meaning.

\section{B. Metaphoric Proverbs}

In metaphoric proverbs, a nominal becomes metaphoric due to its interaction with another proverb constituent, or the nominal symbolizes some characteristic attribute. An example of the first is, Favor will as surely perish as life, and of the second, Fair play is a jewel.

C. Metonymic Proverbs 
This type of proverb is based on association between something literally named and the thing intended. One example of a metonymic proverb is " who has a fair wife needs more than two eyes" in which the eye stands metonymically for the" sight".

\section{Hyperbolic Proverbs}

According to Norrick (ibid: 131) "hyperbole has traditionally been considered a rhetorical figure along with, if not quite of the same importance of synecdoche, metaphor and metonymy." In fact hyperbole counts as amplification. Amplification says more than necessary. For example the proverb "faint heart never won fair lady" is a hyperbolic proverb due to the existence of never in it.

\section{E. Paradoxical Proverbs}

Proverbs in which there is a contradiction or whose interpretation entails a logical contradiction are considered as paradoxical proverbs. In fact paradoxical proverbs have a "second interpretation". An example of paradoxical proverb is " fair is not fair, but that which pleases". The first clause of this proverb asserts a clear logical contradiction. The proverb "a man's house is heaven and hell as well" is a paradoxical proverb as well.

What is called proverb, parable or idiom in Persian is divided into some categories in western cultures. Of course these categories are to somehow overlap (Moosavi, 2000: 1-10). Proverbs are divided into the following classifications:

A) Adage

An old saying that has been accepted as true. It is a fable.

English proverb: "look before you leap"

Persian equivalent: "bi godar be aab nazan"(Don't go near the water until you learn how to swim).

B) Aphorism: A short, cleverly phrased saying which is intended to express a general truth, short explanation, aphorism.

English proverb: "Experience is the name every one gives to their mistakes."

Persian equivalent: "tajrobeh esmist ke hark as ruye eshtebahatash migozarad"

C) Apothegm: "A short, pithy, and instructive saying".

English proverb: "Beverity is the soul of wit".

Persian equivalent: "kam gooy o gozideh gooy chon dor"(speak little and use valuable words).

D) Axiom: "A principle that needs no proof because its truth can be plainly seen".

English proverb: "No one lives for ever".

Persian equivalent: "bashassssr fani ast"

E) Cliché:" A worn-out idea or a trite expression (an expression that has become stale from too much use).

English proverb: "As quick as a wink".

Persian equivalent: "dar yek cheshm be ham zadan" (just in a moment when you close and open your eyes).

F) Expression: A word or group of words used in a particular situation or by particular people. Expressions are divided into colloquial, idiomatic or slang expressions.

English proverb: "Can of words".

Persian proverb: " kaare doshvaar, masaleye por dardesar".

G) Idiom: "A phrase or expression that has a meaning different from what the words suggest in their usual meaning ".

English proverb: "Have bitten off more than you can chew".

Persian proverb: "loghmeye bozorgtar az dahaan bardashtan" (take a gulp much bigger than your mouth).

H) Maxim: "short saying that has become a rule of conduct. A brief statement of a general truth."

English proverb: "Smaller is always better."

Persian proverb: "felfel nabin che rizeh beshkan bebin che tizeh"(don't look at the small size of pepper crack it open and see how bitter it is).

I) Proverb: "An old and familiar saying that tells something wise. A frequently used saying that gives advice or makes a philosophical observation."

English proverb: "The appetite grows eating".

Persian equivalent: "eshtehaa zire dandaan ast"(your appetite is under your teeth).

J) Saw: "A wise saying ".

English proverb: "A stitch in time saves nine."

Persian equivalent: " alaajeh vaaghe'e ghabl az voghu' baayad kard"(event should be taken before it happens).

k) Saying: "A well known and wise statement, which often has a meaning that is different from the meaning of the words it contains."

English proverb: "Wast not, wont not".

Persian equivalent: "tabzir nakon keh dar namaani"(don't waste in order not to be needy).

L) " Informal language, which might include words and meanings which are not polite and which might say in use only for a short time. It is used by particular groups of people who know each other and is usually spoken rather than written. They are appropriate for formal writing.

In Persian the word "joojeh (chiken) is used to show coward persons."

M) Truism: A statement that almost everybody knows is true. 
English proverb: "You are only young once."

Persian equivalent: "Javaani kojaaee ke yaadat beh kheir "(O' youth ! where are you , we bless you).

\section{FUNCTIONS OF PROVERBS}

All or virtually all cultures possess a repertoire of formulations and use them mainly as rhetorically effective means of transmitting accumulated knowledge and experience. Proverbs are speech entities that can be used in every aspect of discussions such as poetry, wise saying, and contemplative argument as well as daily lives of all cultures to address situations or just in leisurely discourse. Mieder (2004: 108-9) mentions that "proverbs are found in many parts of the world, but some areas seem to have richer stores of proverbs than others (such as West Africa), while others have hardly any (North and South America). As far as the functions of proverbs are concerned, Honeck (1997:26-29) has proposed the following functions for the proverbs:

\section{A. Literary Function}

Proverbs are used in prose, poetry and song. The reasons vary with the genre. Poetry and song tend to follow certain rhythmic structures, so the poetic and balanced syntactic structure of some proverbs can be appealing. In addition, they pack a great deal of information into a short statement and poets and song writer often have verbal economy as a goal. For writers of prose and some poetry, the goals may be different, with a shift in a focus to the rhetorical, sometimes indirect, distant style that typifies proverbs. Perhaps the most fundamental reason why proverbs appear in literary sources is that they pack an emotional and aesthetic punch. This effect can be traced not only to their frequent use of poetic devices, but to their common omnitemporal (timeless) form and their arousal of affect-laden universal ideas about human affairs. Writers such as Shakespeare, Emily Dickinson and Bernard Shaw have applied proverbs in their works.

Then, Honeck (ibid, 27) makes this hint that "one can ask whether there is anything unique about the proverbs genre that makes for its use in literature. One hypothesis is that proverbs are detachable from their original context of use, but nevertheless can remind a reader of the social norms they embody that is, the proverbs can retain its general significance in spite of its being resituated in some text".

\section{B. Practical Function}

The other function which Honeck (ibid) clarifies for the proverbs is their use in practical situations. Proverbs have characteristic properties that make them useful for everyday purposes. They are relatively short, poetic, typically concrete, and used as indirect comments. They have the power and wisdom of many people behind them, and they perform categorization and pragmatic functions. These properties strongly suggest that they can be used to facilitate memory, teach and persuade. Of course, these properties are precisely why many proverbs develop in cultures in the first place. Regarding the practicality of proverbs he adds "the proverbs are also used for treatment for sociopsychological problems such as substance abuse, psychotherapy, tests of mental status, as a way of teaching children to think more abstractly, as an imaginary mnemonic by the elderly, as a means of assessing workers' attitudes about work and life, and even as tests of a defendant's competency to stand trial.

According to Moosavi (2000: 8-10) proverbs might be used for either of these functions;

1. Proverbs are used as a title of a book or title of a literary work on the whole (e.g. Shakespeare's measure for measure whose Persian equivalent is " kolukh andaz raa paadaash sang ast")

2. In press, hot news is circulated through a proverb in the heading or text of it which reflect news topic.

3. Statesmen and government authorities use proverbs in their speech in different occasions.

4. Proverbs might attract consumers' attention in ads (either commercial or political).

\section{IMPORTANCE OF PROVERBS}

Disraeli (quoted in Trench 1853:4) points out the importance of proverbs in the following way:

"Proverbs embrace the wide sphere of human existence, they take all the colors of life, they are often exquisite strokes of genius, they delight by their airy sarcasm or their caustic satire, the luxuriance of their humor, the playfulness of their turn, and even by the elegance of their imagery, and the tenderness of their sentiment. They give a deep insight into domestic life, and open for us the heart of man, in all the various states which he may occupy; a frequent review of proverbs should enter into our readings; and although they are no longer the ornaments of conversation, they have not ceased to be the treasuries of thought."

Regarding the importance of proverbs, Mieder (2004:1) asserts that:

Of the various verbal folklore genres (i.e., fairy tales, legends, tall tales, jokes, and riddles), proverbs are the most concise but not necessarily the simplest form. The vast scholarship on proverbs is ample proof that they are anything but mundane matters in human communication. Proverbs fulfill the human need to summarize experiences and observations into nuggets of wisdom that provide ready-made comments on personal relationships and social affairs. There are proverbs for every imaginable context, and they are thus as contradictory as life itself.

He adds that "proverb pairs like "Absence makes the heart grow fonder" and "Out of sight, out of mind" or "Look before you leap" and "He who hesitates is lost" make it abundantly clear that proverb do not represent a logical 
philosophical system. But when the proper proverb is chosen for a particular situation, it is bound to fit perfectly and it becomes an effective formulaic strategy of communication".

Regarding the importance of proverbs at the present time he points out that:

Contrary to some isolated opinions, proverbs have not lost their usefulness in modern society. They serve people well in oral speech and the written word, coming to mind almost automatically as prefabricated verbal units. While the frequency of their employment might well vary among people and contexts, proverbs are a significant rhetorical force in various modes of communication, from friendly chats, powerful political speeches, and religious sermons to lyrical poetry, best-seller novels, and the influential mass media. Proverbs are in fact everywhere, and it is exactly their ubiquity that has led scholars from many disciplines to study them from classical times to the modern age. There is no doubt that the playful alteration of the proverb "If the shoe fits, wear it" to "If the proverb fits, use it" says it all! (Mieder, 2004:2).

Honeck (1997: 4) has argued that the history of proverbs within the species is sketchy, it is clear that the proverb has fascinated the lay person as well as the scholar. Paremiology, the study of proverbs, is practiced by many different kinds of people including cultural anthropologists, psychologists, folklorists, linguists, sociologists, educators, psychiatrists, historians, students of religion, literature buffs, and even lawyers, advertising executives, management consultants, and an occasional proverb aficionado. All these sentences imply the importance of proverbs.

As Honeck (1997:5-6) points out all these interest in and resulting vast literature on the proverb has yielded different goals, perspectives, assumptions, methodologies, findings, and theoretical conclusions in such a way that there is "no overarching theory of proverbs". Instead different views regarding have emerged. He himself refers to seven reasonably distinguishable of such views which have been presented below:

Personal: The proverb is treated from a subjective viewpoint based purely on personal experience and understanding.

Formal: This is a scientific approach that primarily uses the methods and concepts of linguistics, logic, and semiotics to define, classify and semiotics to define, classify and otherwise analyze proverbs.

Religious: Religious teaching and wisdom are examined in texts.

Literary: Proverbs in prose and poetry re analyzed in terms of their literary value and what they tell us about the writer, their times, and so forth.

Practical: The many uses of the proverb in intelligence testing, psychotherapy and other areas are examined.

Cultural: This is a scientific approach to the proverb that treats it as a multifunction from of folk literature that arises from and is embedded in a sociocultural context.

Cognitive: this is a scientific approach based on cognitive science that attempts to explain how individuals use and understand proverbs.

Each of these views has something unique and positive to contribute to our knowledge of proverbs. As it was said the vast area in which proverbs has been investigated by different scholars imply the importance of proverbs as an integral part of all or virtually all cultures and languages.

Learning culture through proverbs:

According to Samover et al (2009: 29) in nearly every culture, proverbs-communicated in colorful, vivid languages and with very few words- offer an important set of values and beliefs for members of the culture. They also reflect the wisdom, biases, and even superstitions of a culture. Proverbs go by many names (such as maxims, truisms, and even sayings), yet they all are intended to carry the truths and accumulated insights of the culture. Proverbs are so important to the learning process that there is even a German proverb that notes, "A country can be judged by the quality of its proverbs."

Proverbs are learned easily and repeated with great regularity. Because they are brief (a line or two), their power as a teacher is often overlooked. These proverbs survive so that each generation learns what a culture deems significant. As Sellers tells you, "proverbs reunite the listener with his or her ancestors". Samovar et al (2009: 30) also mentions that because all people, regardless of their culture, share common experiences, many of the same proverbs appear throughout the world. For example, in nearly every culture some degree of thrift and hard work is stressed. Hence in Germany the proverb states, "One who does not honor the penny is not worthy of the dollar." In the United States people are told, "A penny saved is a penny earned." Because silence is valued in Japan and China, a Japanese proverb says, "The quacking duck is the first to get shot". In addition to numerous universal proverbs, there are also thousands of proverbs that each culture uses to teach lessons that are unique to that particular culture.

Roy (quoted in Samover et al, 2009: 30) offers a summary as to why the understanding of cultural proverbs is a valuable tool for students of intercultural communication.

"Examination of these orally transmitted values offers an excellent means of learning about another culture because the oft-repeated sayings fuse past, present, and future. These sayings focus our attention on basic principles accepted within the culture."

Yet, each culture has proverbs that are unique to it. The saying, 'If you want to know a people, know their proverbs' illustrates this. For example, as Zona, (1994, quoted in Schuster) mentions "sayings from various Native American tribes often reflect their view of the land as sacred: "Take only what you need and leave the land as you found it" and the importance of spirituality: "Wisdom comes only when you stop looking for it and start living the life the Creator 
intended for you". Japanese proverbs often refer to morals: "An evil deed remains with the evildoer" and discretion: "The tongue is like a sharp knife, it kills without drawing blood".

\section{THE ORIGIN OF PROVERBS}

According to Marvin (1922:4) "the origin of most proverbs is unknown.'They were anterior to books,' says Disraeli, 'and formed the wisdom of the vulgar, and in the earliest ages were the unwritten laws of morality.' As a nation's proverbs predate its literature it is impossible to trace them to their beginnings. They spring from an unknown source, increase in volume as they roll on and are adopted by all as unconsciously as they have sprung into existence."

He also points out that in youth we thought that the proverbs quoted by our elders were mere "ways of speaking," borrowed from others of their own generation. As we grew older and sought to discover from whence they came we were surprised to learn that many, if not all of them, had been used for centuries not only by our forbears but all over the world.

Regarding the origins of the proverbs Meider (2004), the famous paremiologist, states that:

Proverbs, like riddles, jokes, or fairy tales, do not fall out of the sky and neither are they products of a mythical soul of the folk. Instead they are always coined by an individual either intentionally or unintentionally, as expressed in Lord John Russell's well-known one-line proverb definition that has taken on a proverbial status of sorts: 'A proverb is the wit of one and the wisdom of many' (9).

He also explains how a statement can turn into a proverb. He believes that if the statement contains an element of truth or wisdom, and if it exhibits one or more proverbial markers, it might "catch on" and be used first in a small family circle, and subsequently in a village, a city, a region, a country, a continent, and eventually the world. The global spread of proverbs is not a pipe dream, since certain ancient proverbs have in fact spread into many parts of the world. Today, with the incredible power of the mass media, a newly formulated proverb-like statement might become a bona fide proverb relatively quickly by way of the radio, television, and print media. As with verbal folklore in general, the original statement might well be varied a bit as it gets picked up and becomes ever more an anonymous proverb whose wording, structure, style, and metaphor are such that it is memorable.

Furthermore, Meider (ibid: 10-13) mentions that it is usually quite difficult to trace the origin and history of a proverb in a particular language. So, studying European languages he proposes four sources for the distribution of European proverbs. Of course he clarifies this point that similar issues have occurred in the dissemination of proverbs in Asian, African, and other linguistic and cultural groups. Here these four sources will be outlined briefly:

1. There is no doubt that a considerable corpus of common European proverbs can be traced back to classical times (Greek and Roman antiquity). Since they were loan translated from the same sources, they exist in the many languages of Europe in identical forms. Little wonder then that exact equivalents of the classical proverb "Where there is smoke, there are fire" can be found in 54 European languages.

2. A second source of proverbs for the entire European continent and beyond is the Bible, whose proverbs date back to classical antiquity and early wisdom literature. As a widely translated book, the Bible had a major influence on the distribution of common proverbs since the various translators were dealing with the same texts. Several dozen biblical proverbs are thus current in identical wordings in many European languages, even though speakers might not remember that they are employing proverbs from the Bible.

3. The third source for common European proverbs is Medieval Latin. It must not be forgotten that the Latin language of the Middle Ages had the status $f$ a lingua franca, and as such it developed new proverbs that cannot be traced back to classical times. Many Medieval Latin proverbs in their exact translations have spread to European languages, and they certainly belong to some of the most popular proverbs today. Many Medieval Latin proverbs in their exact translations have spread to European languages, and they certainly belong to some of the most popular proverbs today. A well-known example is: "Crows will not pick out crows' eyes".

4. The fourth source for common European proverbs reverses the historical move of proverbs from Europe to the United States. They are modern texts that have been disseminated since the middle of the twentieth century Proverbs throughout Europe by means of the mass media. A few American proverbs that are already spreading across the European continent either in the new lingua franca of English or in new loan translations are "A picture is worth a thousand words," "It takes two to tango," and "Garbage in, garbage out" (from the world of computers).

As far as the origins of proverbs in Persian language is concerned Moosavi (2000: 4) in his book, mentions two origins from which proverbs emerge. These two are as follows:

Religion:

\{In these kinds of proverbs we can find words, expressions or meaning which have their origin in one religion. Their equivalents in another language may be a religious one, non- religious one or none . Some examples of Persian are given whose equivalents in English are as follows:

1) PP: "Hamisheh Sha'boon yekbar ramezoon"(always the month of Sha'ban once Ramezan (Sha'ban and Ramezan are respectively the eighth and ninth lunar months)).

EP: "Always the bride's maid never the bride".

2) PP: "Har keh raa kholghash nekoo nikoo shomar"(every one who is good-tempered, consider him as a good person) EP: " Handsome is that handsome does" 
Literature:

\{The proverbs with this origin are those that have originated from literary works written in one language. These might be one line of a poem, one sentence or phrase taken from a fable or mythological story or from a moral exhortation .

1)"Har kas tohi kisetar aasudetar"(Emptier sack, more comfortable).

EP: "Small riches hath most rest".

2)"Hezaar va'deye khubaan yeki vafaa nakonad"(good person with thousands promises only does one)

EP: "He that promises too much means nothing".

3)"Nushdaaru ba'd az marge Sohraab"(Nushdaaru after the death of Sohrab(one mythological character in Persian literature)).

EP: "While men go after a leech, the body is buried."

4)"omr barf ast o aaftabe tamooz" (life is like snow against summer sunshine.)

EP: "The shades of time are running out."

\section{ON THE TRANSLATION OF PROVERBS}

Translating proverbs, the translator should know linguistic and non-linguistic features of both languages. By linguistic features we mean those elements which are not conveyed only through words, what is important here is culture. Each proverb conveys specific meaning in a specific context of situation. Therefore, a proverb should be rendered with care to carry the same cultural conventions in the original proverb. It is not reasonable to translate a proverb while just looking at the first meaning of its words in a dictionary.

Mollanazar (2001: 54) emphasized that proverbs cannot be translated literally (word-for-word) and they may sometimes have no natural figurative equivalents in TL. Thus, he proposed two strategies in translating proverbs:

a) Some similar proverbs can be found in the two languages with more or less similar form, vocabulary and meaning and;

b) Many proverbs may be found in the two languages which have similar meanings and can be applied in the same contexts, but they have different form and vocabulary.

Beekman and Callow (in Gorjian, 2006) suggested three ways to translate a proverb which are as follow:

1. The words following the proverb could be introduced as the meaning of the proverb;

2. It can be replaced with an equivalent local proverb; and

3. Its non-figurative meaning could be stated straight forwardly.

As far as the translation of proverbs is concerned Falk (1978: 44) says that "since idioms, proverbs and certain nonproductive compounds must be entered in the lexicon of a grammar as single units as if they were single morphemes, it is not surprising that these items pose difficulties when translation from one language to another is involved".

Baker (1992:65) has proposed four strategies for the translation of idioms and fixed expressions including proverbs which are as follow:

1. Using an idiom of similar meaning and form of SL one.

2. Using an idiom of similar meaning but dissimilar form of SL idiom.

3. Translation by paraphrase, and

4. Translation by omission

Duff (in Gorjian, 2006) cited that "idiomatic expressions are notoriously untranslatable. These include similes, metaphors, proverbs and sayings (as good as jargon, slang, and colloquialisms)." Duff also noted that if these expressions have no equivalents in TL, the translator may approach to TL equivalents as follows:

1. Literal translation,

2. Original word in inverted commas,

3. Close equivalents, and

4. Non-idiomatic translation.

Finally, Duff (ibid) emphasized that if there is not an appropriate equivalent in TL, the translator should not force it into the translation. Vinay and Darbelnet (1995: 342) believed that the TL equivalents should "replicate the same situation as in the original, whilst using completely different wording." This approach can be used to maintain the stylistic impact of the SL text in the TL text. According to them, an equivalent is the ideal method when the translator has to deal with proverbs, idioms, clichés, nominal or adjectival phrases and the onomatopoeia of animal sounds.

\section{CONCLUSION}

Proverbs are interesting, important, and complex. That is why so many different views have evolved to analyze them: the personal, formal, religious, literary, practical, cultural and cognitive views. These views have different goals that have been persuaded with different techniques, so they provide us with different information. Proverbs have been and remain most powerful and effective instrument for the transmission of culture, social morality, manners and ideas of a people from one generation to another. The reason behind the efficacy of them has been and remains a most powerful and effective instrument for the transmission of culture, social morality, manners and ideas of a people from one 
generation to another. The reason behind the efficacy of the proverb is that it is an aphorism, a wise saying based upon people's experience, and is a reflection of the social values and sensibility of the people.

\section{REFERENCES}

[1] Arora, S. (1984). The Perception of Proverbiality. Retrieved June, 10, 2010 from http //www.wikipedia.com//.

[2] Baker, M. (1992). In Other words: a course book on translation. London and New York: Routledge.

[3] Falk, J. (1978). Linguistics and language: a survey of basic concepts and implication. $2^{\text {nd }}$ Ed, Canada: Michigan University Press.

[4] Gorjian. B. (2006). Translating English proverbs into Persian: A case of comparative linguistics.

[5] Honeck, R. (1997). A proverb in mind: the cognitive science of proverbial wit and wisdom. USA: Lawrence Erlbaum.

[6] Marvin, D.E. (1922). Antiquity of Proverbs. New York and London: G.P PUTNAM SONS.

[7] Mieder, W. (2004). Proverbs: A Handbook. London: Greenwood Press.

[8] Meider, W. Dundes, A. (1995). The Wisdom of Many: Essays on the Proverb, (Ed). NewYork: Garland.

[9] Mollanazar, H. (2001). Principles and methodology of translation. Tehran: SAMT.

[10] Moosavi, M. (2000). Prose and Poetic Dictionary of Persian Proverbs and their English Equivalents. Tehran: Jahanrayaneh.

[11] Norrick, N.R. (1985). How Proverbs Mean? Semantic Studies in English Proverbs. Amesterdom: Mouton.

[12] Schuster. E. (1998). Proverbs: A Path to Understanding Different Cultures. Journal of Extension, 36.1, 18-23.

[13] Samovar, Larry A., Richard E. Porter, and Lisa A. Stefani. (2009). Communication between Cultures. Edited by Randall Adams. Third ed, Wadsworth Series in Communication Studies. Belmont, CA: Wadsworth Publishing.

[14] Trench, C.R. (1853). On the Lessons in Proverbs. New York: Redfield.

[15] Vinay, J. P., \& Darbelnet, P. (1995). Comparative stylistics of French and English: A methodology for translation. translated by J.C. Sager \& M. J. Hamel. Amsterdam and Philadelphia: John Bebjamins.

Azizollah Dabaghi completed his doctoral studies in language learning and teaching at the University of Auckland after being awarded with the University's prestigious Doctoral Scholarship.

He has been involved in translation field for the last thirty years most which was spent in practical works as a Spontaneous Oral Translator in international relations. He also spent some years working as a Translator of official and legal deeds at the University of Isfahan, Iran. Currently, he is an Assistant Professor at the University of Isfahan, teaching and researching language acquisition and translation courses at both undergraduate and post-graduate levels. His main interests include translation and culture, legal translation, sociolinguistics, and second language acquisition.

Elham Pishbin is a post graduate student of English translation in Isfahan University, Iran. She received her B.A degree in English translation from Mobarakeh University, Isfahan, Iran.

Now she is a freelance translator in Isfahan, Iran. Her article, How to translate Irony, has been published in Article Niche (July, 6, 2010) and her book titled the Big Book of Parenting Solutions will be published by the end of October. Her interests are legal translation and teaching foreign languages.

Leila Niknasab is a post graduate student of English translation in Isfahan University, Iran. She received her B.A degree in English Literature from Qom University.

For the time being she works as a Part-time Translator and English Teacher in language institutes, Isfahan, Iran. She has given her article titled Translation and Culture: Allusions as Culture Bumps published in Article Niche (May 18, 2010), and her book titled Anger Management Games for Children is in press. Literary translation and cultural studies are some of her interests. 